\title{
Pulmonary toxicity of mTOR inhibitors in kidney transplantation: A single-center experience
}

\author{
Patrícia Valério ${ }^{1}$, Rita Calça², Rita Veríssimo², Francisca Silva ${ }^{3}$, Alexandra Atalaia ${ }^{4}$, Tiago Saldanha4, and \\ André Weigert ${ }^{2}$
}

${ }^{1}$ Nephrology Department, Centro Hospitalar de Setúbal, Setúbal; ${ }^{2}$ Kidney Transplantation Unit, Hospital de Santa Cruz, Centro Hospitalar de Lisboa Ocidental, Lisboa; ${ }^{3}$ Nephrology Department, Centro Hospitalar do Funchal, Funchal; ${ }^{4}$ Pharmaceutical Services, Hospital de Santa Cruz, Centro Hospitalar de Lisboa Ocidental, Lisboa; ${ }^{5}$ Imaging Department, Centro Hospitalar de Lisboa Ocidental, Lisboa. Portugal

\begin{abstract}
Objective: The purpose of this report was to describe the clinical features of mammalian target of rapamycin inhibitors (mTORi) pulmonary toxicity in kidney recipients. Material and methods: We analyzed clinical, analytical, and image data of all kidney recipients who were immunosuppressed with everolimus or sirolimus, between 2013 and 2018. Results: From a pool of 379 recipients, 12 presented evidence of mTORi-induced hypersensitivity pneumonitis. The median age at onset of pneumonitis was 62.8 years. The majority had chronic graft dysfunction, with a median serum creatinine of $1.9 \mathrm{mg} / \mathrm{dL}$. All patients were under mTORi for at least 2 years. The most common symptoms were cough and fever. Chest computerized tomography documented ground-glass opacities and lower lobe involvement in all patients. Two required mechanical ventilation, one of which died (the only dead in this series). Conclusions: The size of this sample does not allow inferring about risk factors or prognosis predictors. However, most patients were male, with chronic graft dysfunction and exposure to mTORi for at least 2 years. MTORi-induced pneumonitis is rare but potentially fatal. It should be included in the differential diagnosis of pulmonary conditions in these patients.
\end{abstract}

Key words: Hypersensitivity pneumonitis. Mammalian target of rapamycin inhibitors. Kidney transplantation. Pulmonary toxicity.

\section{Toxicidad pulmonar de los inhibidores de mTOR en pacientes con trasplante de riñón: experiencia de un centro}

\section{Resumen}

Objetivo: El propósito de este trabajo fue describir las características clínicas de la toxicidad pulmonar de mTORi en receptores renales. Materiales y métodos: Analizamos datos clínicos, analíticos e de imagen de los pacientes con trasplante de riñón imunossuprimidos con everolimus (EVR) o sirolimus (SRL), entre 2013 y 2018. Resultados: De un grupo de 379 receptores, 12 presentaron evidencia de HP inducida por mTORi. La mediana de edad al inicio de la neumonitis fue 62,8 años. La mayoría presentaba disfunción crónica del injerto (creatinina mediana de 1,9 mg/dL). En el diagnóstico, todos los pacientes estaban imunossuprimidos con mTORi durante al menos 2 años. Los síntomas más comunes fueron

\footnotetext{
Correspondence:

*Patrícia Valério

E-mail: p.valerios89@gmail.com

Date of reception: 19-05-2021

Date of acceptance: 12-10-2021

DOI: 10.24875/NEFRO.21000019

Disponible en internet: 27-12-2021

Nefro Latinoam. 2021;18:103-110

www.nefrologialatinoamericana.com

2444-9032/@ 2021 Sociedad Latinoamericana de Nefrología e Hipertensión. Publicado por Permanyer. Este es un artículo open access bajo la licencia CC BY-NC-ND (http://creativecommons.org/licenses/by-nc-nd/4.0/).
} 
Nefro Latinoam. 2021;18

tos y fiebre. La tomografía computarizada de tórax documentó opacidades en vidrio deslustrado y afectación del lóbulo inferior en todos los pacientes. Dos requirieron ventilación mecánica, uno de los cuales falleció. Conclusiones: El tamaño de esta muestra no permite inferir sobre factores de riesgo o de pronóstico. La mayoría de los pacientes eran hombres, con disfunción crónica del injerto y exposición a mTORi durante al menos 2 años. La neumonitis inducida por mTORi es rara pero potencialmente mortal. Debe incluirse en el diagnóstico diferencial de afecciones pulmonares en estos pacientes.

Palabras clave: Inhibidores de mTOR. Neumonitis por hipersensibilidad. Trasplante de riñón. Toxicidad pulmonar.

\section{Background}

Mammalian target of rapamycin inhibitors (mTORi) are antiproliferative agents with a wide spectrum of actions, used as immunosuppressant in solid organ transplantation (heart, lung, and kidney) and as antineoplastic agents. However, these drugs are associated with a great number of potential side effects that could involve almost all organ systems ${ }^{1,2}$.

After SYMPHONY trial showed low-dose calcineurin inhibitors superiority, mTORi use as immunosuppressant decreased during the second decade of XXI century. However, recent evidence resuscitates mTORi role in kidney transplantation (KTx) immunosuppression, as an option in low-/moderate-risk patients ${ }^{3,4}$. Despite this, mTORi remained essential in the setting of calcineurin inhibitors toxicity, Kaposi sarcoma, lymphomas including Epstein-Barr virus-related post-transplant lymphoproliferative disorders, and skin and kidney neoplasms ${ }^{5,6}$. Furthermore, they are the favorite agents in the setting of viral diseases including cytomegalovirus ${ }^{7,8}$ and human polyomavirus ${ }^{9,10}$. FinaIly, mTORi may replace mycophenolate due to its side effects, including neutropenia and gastrointestinal complaints.

Hypersensitivity pneumonitis (HP) is a rare adverse effect, initially described in patients under SRL, probably because this was the first approved mTORi, but more recently recognized as a class side effect ${ }^{11,12}$. The lack of uniform diagnostic criteria led to wide reported incidence rates ${ }^{13}$.

The exact pathophysiology is unknown, with both immune-mediated and direct toxicity mechanisms already described. A dose-dependent mechanism is suspected, because HP rates are higher in the oncology setting, as higher doses are used when compared to solid organ transplantation ${ }^{12,13}$. An immunological mechanism was suggested because of the lymphocytosis and eosinophilia is detected on bronchoalveolar lavage (BAL) (see ahead). Delayed T-cell-mediated hypersensitivity has also been described ${ }^{1,12-14}$.
HP develops only in a minority of exposed individuals, suggesting either genetic predisposition or simultaneous exposure to another trigger. Risk factors include a late switch to mTORi and impaired kidney func$\operatorname{tion}^{13,15}$. For SRL, male sex and a higher age are also considered risk factors. There is no association with a history of smoking, chronic obstructive pulmonary disease, or abnormal baseline pulmonary function test $^{13}$.

MTORi-induced HP is mainly asymptomatic, or just mildly symptomatic with dry cough, dyspnea, hypoxia, occasionally with hemoptysis and systemic symptoms, such as fever and fatigue. Rarely, symptoms are severe and may progress to potentially life-threatening disease requiring mechanical ventilation $n^{1,12,13,16,17}$. The reported time for HP onset is wide, from months to years ${ }^{12,13}$.

The non-specific clinical features require exclusion of entities more common in these patients, namely, opportunistic infections, a much more common adverse effect of mTORi use. The diagnosis is also supported by laboratory and imaging studies ${ }^{12,13}$.

A temporal association between drug exposure and HP onset may exist, but previous cases describe a wide temporal window, until up to 6 years after first exposure ${ }^{11}$.

Drug withdrawal is the cornerstone of treatment, but some reports suggest improvement with dose reduction ${ }^{12,13,15,18}$.

The purpose of this report was to describe the clinical features of mTORi pulmonary toxicity in $\mathrm{KTx}$ recipients.

\section{Subjects and methods}

We retrospectively reviewed all KTx recipients form our center, to whom immunosuppression with everolimus (EVR) or SRL was prescribed between 2013 and 2018. We identified 379 recipients under mTORi in that period (303 were under EVR and 158 under SRL; 86 of those patients were initially under SRL and were converted to EVR later). 
We analyzed clinical, analytical, and image data of those recipients, to identify the ones with evidence of respiratory symptoms, with or without constitutional symptoms (fever and fatigue), after mTORi first prescription (in the absence of features to suggest a systemic rheumatic disease). HP diagnosis was established with the presence of typical chest CT findings, BAL lymphocytosis $(>20 \%)$, and response to antigen avoidance. In the presence of the three criteria, histopathologic confirmation is not necessary ${ }^{19}$. Fourteen recipients presented evidence of HP, but two were excluded because we could not exclude pneumonitis due to another cause. Infectious process was excluded based on analytical evaluation (negative C-reactive protein and leukocytes blood count within normal range), BAL results, suggestive chest CT features, and clinical evolution, including improvement after drug withdrawal.

For the 12 recipients with evidence of mTORi-induced HP, we collected demographic and clinical data, namely, comorbidities (including previous respiratory infections/disease), kidney graft function, history of immunosuppression and other medications with recognized pulmonary toxicity (e.g., amiodarone), diagnostic tests, treatments, and outcomes. Until December 2019, all serum creatinine and blood mTORi measurements were performed in the same laboratory.

Data are presented as medians and interquartile range (IQR) or frequencies and proportions whenever appropriate. Data were analyzed using IBM ${ }^{2}$ SPSS version 23.0 (SPSS, Inc., Chicago, IL) statistical software.

\section{Results}

From a pool of $379 \mathrm{KTx}$ recipients, 12 presented evidence of mTORi-induced HP (3.2\%). Table 1 summarizes the patient characteristics (Table 1).

The median age at HP onset was 62.8 (IQR 51.568.9) years. Eleven patients were male, and 10 patients were Caucasian. At the time of HP onset, most patients $(n=11)$ had chronic graft dysfunction, with a median serum creatinine of 1.9 (IQR 1.5-2.3) $\mathrm{mg} / \mathrm{dL}$.

At the time of HP diagnosis, nine patients were under EVR and three under SRL. Four of the patients currently under EVR have been on SRL previously.

Three patients presented at least two lower respiratory infections in the previous year of HP diagnosis. One other patient had two consecutive episodes 3 years before diagnosis. Other three patients had a previous pulmonary disease and two were currently taking another drug with recognized pulmonary toxicity (amiodarone).

All patients had chronic treatment with prednisone and were previously under immunosuppression with calcineurin inhibitors (three with ciclosporin and the remaining with tacrolimus). After $\mathrm{KTx}$, patients were converted to mTORi after a median time of 12.2 (IQR 8.4-34.6) months.

At the time of HP diagnosis, all patients were under mTORi for at least 2 years (median time since mTORi initiation of 85.0 [IQR 44.5-100. ${ }^{4}$ months). At diagnosis, the median through level for EVR was 5.7 (IQR 5.3-6.7) $\mu \mathrm{g} / \mathrm{L}$ and for SRL 3.5 (3.3-3.8) $\mu \mathrm{g} / \mathrm{L}$. Six months before, the median through levels were slightly superior: EVR 7.6 (IQR 4.9-8.4) $\mu \mathrm{g} / \mathrm{L}$ and SRL 6.2 (5.0-11.8) $\mu \mathrm{g} / \mathrm{L}$. However, no through level was in a toxic range.

The most common symptoms were dry cough $(n=8)$ and low-grade fever $(n=5)$. Three patients presented hemoptysis and two referred dyspnea. Chest $\mathrm{CT}^{11}$ revealed ground-glass opacities in all patients and a micronodular pattern in two of them. Lower lobe was involved in all patients and bilateral pulmonary involvement was observed in the majority $(n=10)$. BAL was performed in four patients: three unveiled evidence of lymphocytic alveolitis and the fourth presented no changes. Only two patients performed functional pulmonary tests [FPT], describing a restrictive pattern.

Two patients required mechanical ventilation, and one of them eventually died during intensive care unit (ICU) admission (the only death in this series). All but one patient had clinical improvement after withdrawal of mTORi and reconversion to calcineurin inhibitors. We present the radiographic evolution of patient number 5 (Figs. 1 and 2), unveiling a dramatic improvement of the detected changes within 3 months of mTORi withdrawal, with simultaneous clinical improvement. Two patients were additionally treated with increased doses of systemic corticoid.

Seven patients repeated the chest CT scan, showing radiologic improvement, within a median time of 3.4 (IQR 2.7-10.7) months.

\section{Discussion}

Initial reports of HP related with mTROi were attributed to SRL, the first of this class to be appro$\operatorname{ved}^{14,15,17}$, and subsequently reports showed a great number of cases related to $E V R^{11}$. In our study, there were more cases related to EVR due to its greater current use.

Several risk factors already described in the literature ${ }^{13,15}$, such as male sex and impaired kidney 


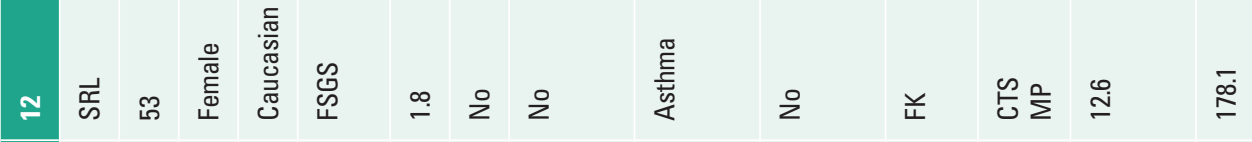

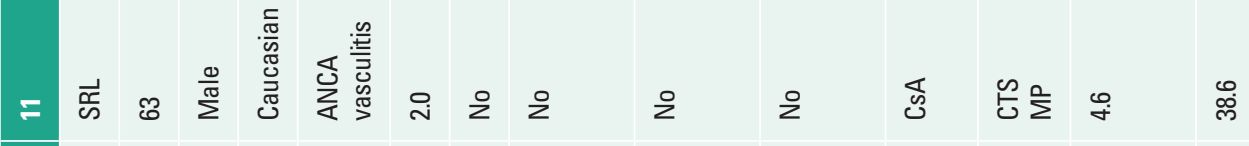

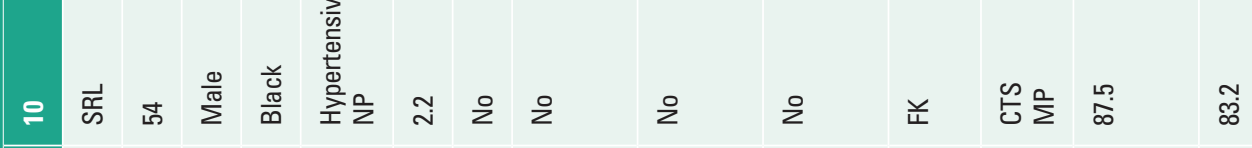

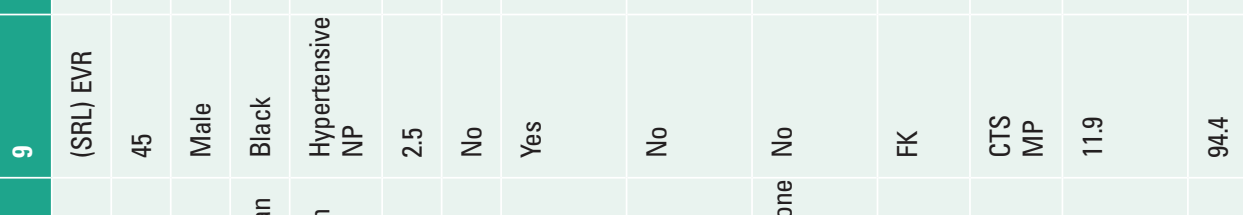

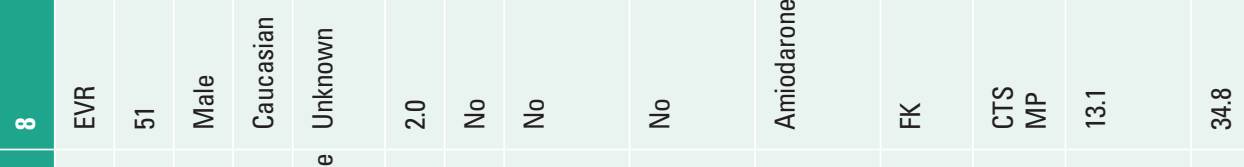
レ

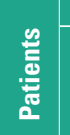

○ 几 + 㐍

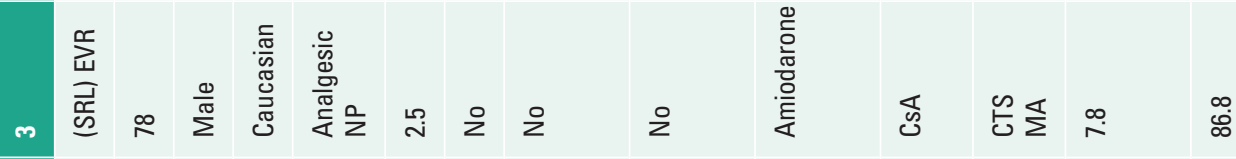

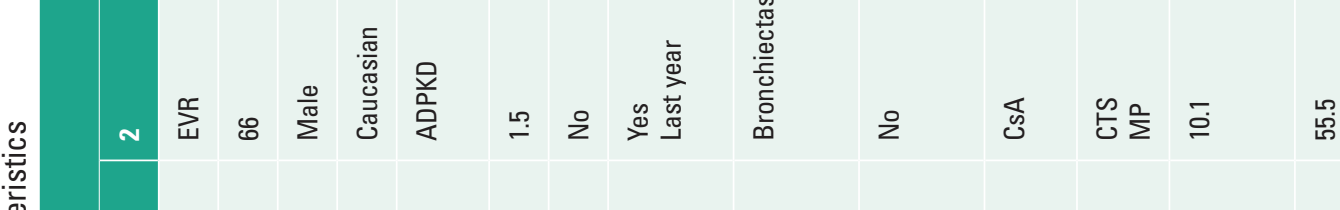

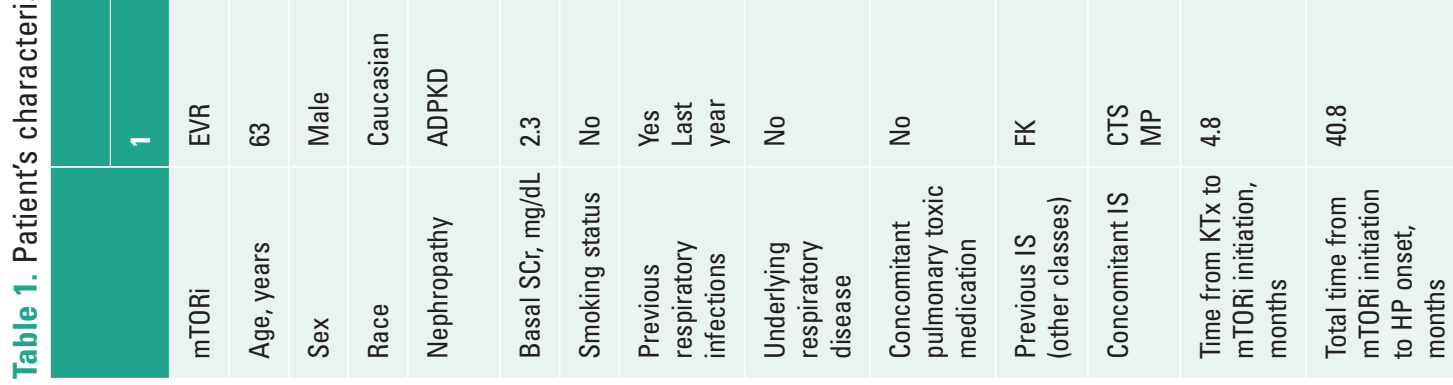




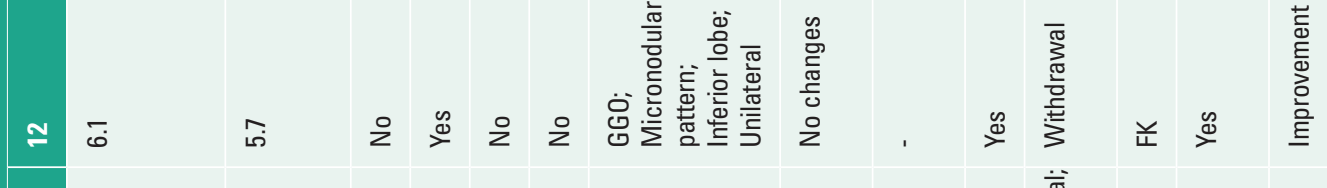

$=$ =

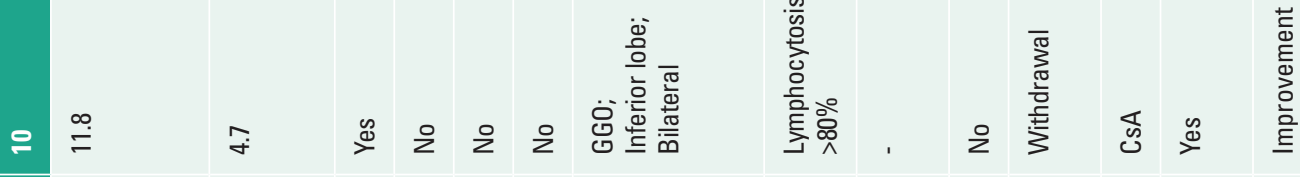

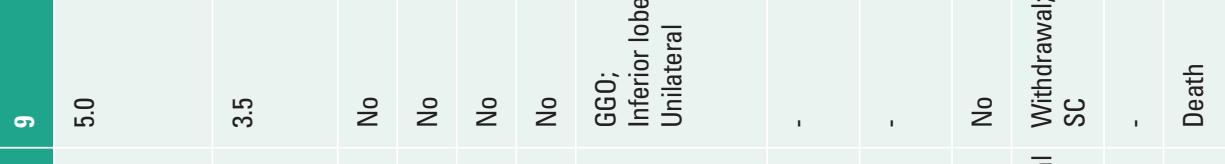

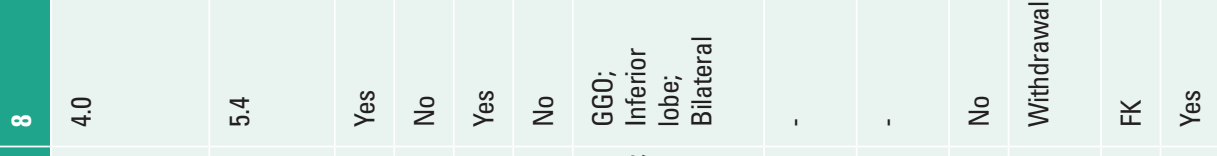

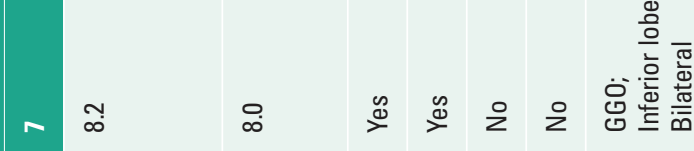

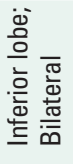

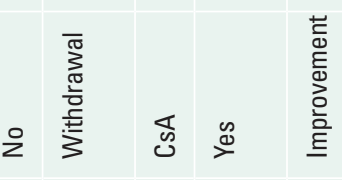

厸

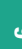

เา

1

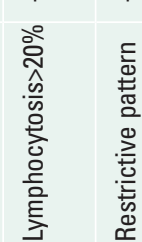

蒠

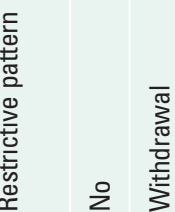

芒 $\stackrel{0}{=}$

之)

-

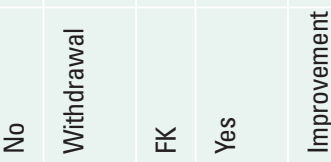

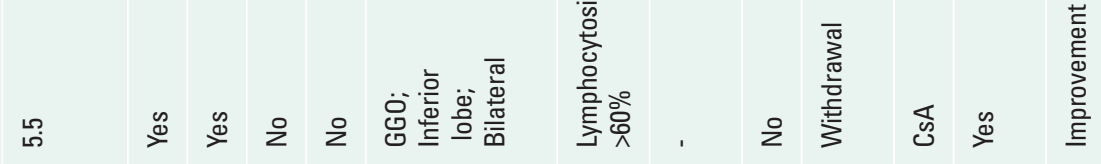




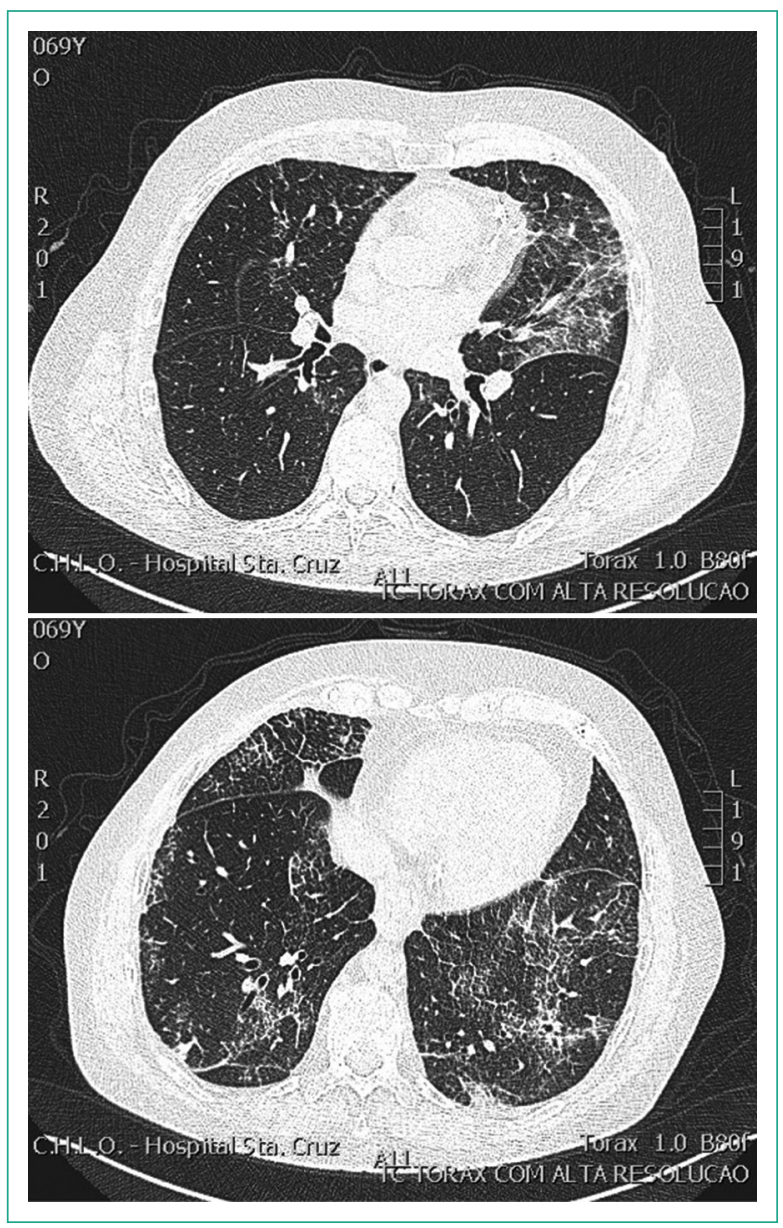

Figure 1. Chest CT from patient number 5, upper and lower views, before mTORi withdraw, showing bilateral ground glass opacities.

function, were also observed in our group of patients. However, there is neither a clear predominance of older patients nor evidence for a later switch to mTORi. All patients were under mTORi for at least 2 years (median time of exposition of 85.0 months), suggesting a tendency to a longer exposure time and cumulative dose before the pneumonitis diagnosis.

Despite a dose-related effect has been suggested, published cases showed both association with supratherapeutic and therapeutic levels ${ }^{15,17}$. In our series, drug through levels were within therapeutic range at HP onset, although slightly elevated 6 months earlier, but never in a toxic range.

The clinical and radiological features of our patients were similar to the ones observed in previous reports. The most prevalent symptoms were dry cough and dyspnea. Half of our patients suffered from recurrent respiratory infections during the time of immunosuppression with mTORi.

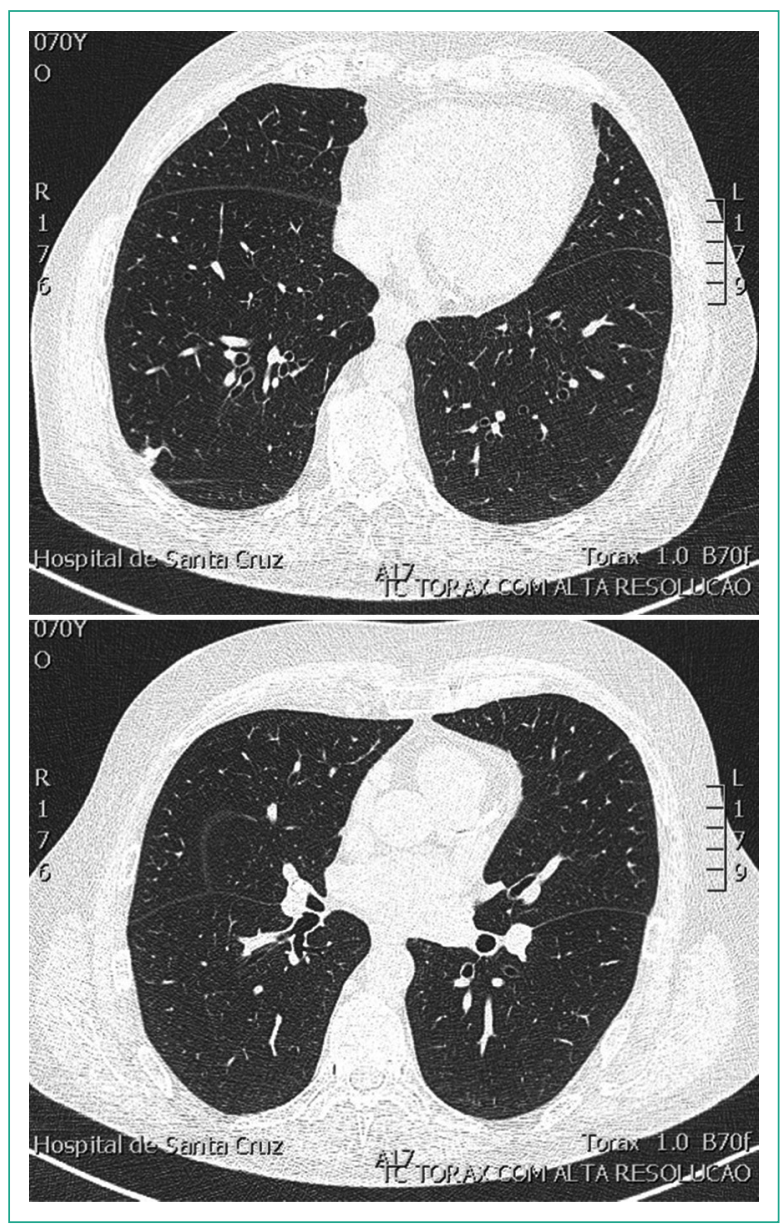

Figure 2. Chest CT from patient number 5, upper and lower views, 3 months after mTORi withdraw, showing a dramatic improvement of the affected areas.

Chest radiography is usually the first step in the evaluation, but it either is normal or reveals nonspecific features. Chest CT may reveal ground-glass opacities, the most common feature, compatible with diffuse alveolar hemorrhage. Although characteristic, this finding may be seen in other disorders, namely, in opportunistic infections, pulmonary edema, and cellular non-specific interstitial pneumonia. A reticular micronodular pattern and focal areas of consolidations are also common. These features were described on high-resolution CT in asymptomatic patients, probably representing the initial pulmonary changes. However, the clinical implications of those changes in the absence of symptoms remain unknown. Usually, the pulmonary abnormalities on CT are bilateral and in the lower lobes $1,13,18$.

BAL is considered the most sensitive diagnostic tool. The typical pattern is lymphocytic alveolitis (lymphocytosis $>20 \%$ ), mainly CD4 $4^{+}$cells, with or without eosinophilia. It may also show evidence of alveolar 
hemorrhage, with macrophage hemosiderosis ${ }^{14,17,18}$. As suggested by Mayo Clinic investigators ${ }^{20}$, these findings suggest two possible HP phenotypes, what probably explains the wide spectrum of symptoms and prognosis: a lymphocytic pneumonitis without alveolar hemorrhage or alveolar hemorrhage without lymphocytic pneumonitis. All things considered, probably, the most specific way to diagnose this entity is to do a thorough diagnostic workup with all the aforementioned studies.

Considering the current pandemic situation, one additional point needs to be highlighted. The possibility of COVID-19 should be considered primarily in immunosuppressed patients with respiratory tract symptoms or severe lower respiratory tract illness with no other apparent cause. Some CT findings of mTORi-induced HP may be similar to features observed in COVID-19, namely, bilateral ground-glass opacities ${ }^{21,22}$. It is essential to compare the current radiological findings with previous chest radiographies or CTs in infected patients under mTORi. It is still uncertain whether infected patients previously under mTORi should have this therapy replaced, particularly in the setting of hypoxemia.

All patients in our series presented typical CT findings. The diagnosis was confirmed by BAL findings in three patients (lymphocytosis) and in the remaining ones, by clinical and radiological improvement with drug withdrawal. In two patients, HP diagnosis was assumed as "probable:" one died short term after the diagnosis; the other patient presented ANCA vasculitis with pulmonary involvement, and chest CT showed acute features suggestive of both diagnosis and chronic characteristics of mTORi pneumonitis (fibrosis in the previous affected lobes).

Drug withdrawal is the cornerstone of treatment, and it should be permanently discontinued in cases of life-threatening HP. Symptoms usually improve after cessation, but certain individuals may develop pulmonary fibrosis by a mechanism not completely understood. In patients with progressive disease, a restrictive pulmonary disease sets in, and FPT may be useful to determine HP severity and to follow clinical evolution ${ }^{13}$.

Treatment with corticosteroids is not widely accepted due to lack of evidence, but it should be considered in selected patients. On the other hand, in certain circumstances, a watchful waiting could be an accepted approach $^{1,12,13,15-18}$.

In our series, all patients interrupted the drug and were reconverted to calcineurin inhibitors and/or mycophenolate. Two patients underwent a course of higher doses of corticosteroids, one during ICU admission (the only death in this series) and the other with a favorable outcome.
The remaining patients evolved favorably, except the one with associated ANCA vasculitis.

\section{Conclusions}

The size of this sample does not allow inferring about risk factors or predictors of prognosis. However, most patients were male, with chronic graft dysfunction and exposure to the drug for at least 2 years. Chest CT was the most relevant complementary means for the identification of this pathology.

In conclusion, mTORi-induced pneumonitis is rare but should not be underestimated, because it can lead to respiratory insufficiency (acutely and chronically) and even death. Therefore, it should be included in the differential diagnosis of pulmonary conditions in these patients because early recognition and treatment are essential.

\section{Conflicts of interest}

The authors have no conflicts of interest to declare.

\section{Funding}

None to declare.

\section{Ethical disclosures}

Protection of human and animal subjects. The authors declare that no experiments were performed on humans or animals for this study.

Confidentiality of data. The authors declare that they have followed the protocols of their work center on the publication of patient data.

Right to privacy and informed consent. The authors have obtained the written informed consent of the patients or subjects mentioned in the article. The corresponding author is in possession of this document.

\section{References}

1. Albiges L, Chamming's F, Duclos B, Stern M, Motzer RJ, Ravaud A et al. Incidence and management of mtor inhibitor-associated pneumonitis in patients with metastatic renal cell carcinoma. Ann Oncol. 2012;23:1943-53.

2. Pharmacology of Mammalian (Mechanistic) Target of Rapamycin (Mtor) Inhibitors; 2020. Available from: https://www.uptodate.com/contents/pharmacology-of-mammalian-mechanistic-target-of-rapamycin-mtor-inhibitors?sear$\mathrm{ch}=\mathrm{mTOR} \% 20$ inhibitor\&source=search_result\&selectedTitle=1 150\&usage_type=default\&display_rank=1 [Last accessed on 2020 Nov ${ }^{21}$.

3. Berger SP, Sommerer C, Witzke O, Tedesco H, Chadban S, Mulgaonkar S, et al. Two-year outcomes in de novo renal transplant recipients receiving everolimus-facilitated calcineurin inhibitor reduction regimen from the transform study. Am J Transplant. 2019;19:3018-34.

4. Cucchiari D, Rios J, Molina-Andujar A, Montagud-Marrahi E, Revuelta I, Ventura-Aguiar $P$, et al. Combination of calcineurin and mtor inhibitors in kidney transplantation: a propensity score analysis based on current clinical practice. J Nephrol. 2020;33:601-10. 
5. Guerra G, Ciancio G, Gaynor JJ, Zarak A, Brown R, Hanson L, et al. Randomized trial of immunosuppressive regimens in renal transplantation. J Am Soc Nephrol. 2011;22:1758-68.

6. Mendez R, Gonwa T, Yang HC, Weinstein S, Jensik S, Steinberg S, et al. A prospective, randomized trial of tacrolimus in combination with sirolimus or mycophenolate mofetil in kidney transplantation: results at 1 year. Transplantation. 2005;80:303-9.

7. Andrassy J, Hoffmann VS, Rentsch M, Stangl M, Habicht A, Meiser B, et al. Is cytomegalovirus prophylaxis dispensable in patients receiving an mtor inhibitor-based immunosuppression? A systematic review and meta-analysis. Transplantation. 2012:94:1208-17.

8. Nashan B, Gaston R, Emery V, Saemann MD, Mueller NJ, Couzi L, et al Review of cytomegalovirus infection findings with mammalian target of rapamycin inhibitor-based immunosuppressive therapy in de novo renal transplant recipients. Transplantation. 2012;93:1075-85.

9. Suwelack B, Malyar V, Koch M, Sester M, Sommerer C. The influence of immunosuppressive agents on Bk virus risk following kidney transplantation, and implications for choice of regimen. Transplant Rev (Orlando). 2012;26:201-11.

10. Moscarelli L, Caroti L, Antognoli G, Zanazzi M, Di Maria L, Carta P Minetti $E$, et al. Everolimus leads to a lower risk of BKV Viremia than mycophenolic acid in de novo renal transplantation patients: a single-center experience. Clin Transplant. 2013;27:546-54.

11. Rodriguez-Moreno A, Ridao N, Garcia-Ledesma P, Calvo N, Di Maria L, Carta $\mathrm{P}$, et al. Sirolimus and everolimus induced pneumonitis in adult renal allograft recipients: experience in a center. Transplant Proc. 2009:41:2163-5.

12. White DA, Camus $P$, Endo M, Escudier B, Calvo E, Akaza $\mathrm{H}$, et al Noninfectious pneumonitis after everolimus therapy for advanced renal cell carcinoma. Am J Respir Crit Care Med. 2010;182:396-403.

13. Willemsen AE, Grutters JC, Gerritsen WR, van Erp NP, van Herpen CM Tol J. Mtor inhibitor-induced interstitial lung disease in cancer patients: comprehensive review and a practical management algorithm. Int J Cancer. 2016;138:2312-21.
14. Morelon E, Stern M, Israel-Biet D, Correas JM, Danel C Mamzer-Bruneel MF, et al. Characteristics of sirolimus-associated interstitial pneumonitis in renal transplant patients. Transplantation. 2001;72:787-90.

15. Weiner SM, Sellin L, Vonend O, Schenker P, Buchner NJ, Flecken M, et al. Pneumonitis associated with sirolimus: clinical characteristics, risk factors and outcome--a single-centre experience and review of the literature. Nephrol Dial Transplant. 2007;22:3631-7.

16. Alexandru S, Ortiz A, Baldovi S, Milicua JM, Ruíz-Escribano E, Egido J, et al. Severe everolimus-associated pneumonitis in a renal transplant recipient. Nephrol Dial Transplant. 2008;23:3353-5.

17. Champion L, Stern M, Israel-Biet D, Mamzer-Bruneel MF, Peraldi MN, Kreis $\mathrm{H}$, et al. Brief communication: sirolimus-associated pneumonitis: 24 cases in renal transplant recipients. Ann Intern Med. 2006;144:505-9.

18. Spagnolo P, Rossi G, Cavazza A, Bonifazi M, Paladini I, Bonella F, et al. Hypersensitivity pneumonitis: a comprehensive review. J Investig Allergol Clin Immunol. 2015;25:237-50.

19. Vasakova M, Morell F, Walsh S, Leslie K, Raghu G. Hypersensitivity pneumonitis: perspectives in diagnosis and management. Am J Respir Crit Care Med. 2017;196:680-9

20. Vlahakis NE, Rickman OB, Morgenthaler T. Sirolimus-associated diffuse alveolar hemorrhage. Mayo Clin Proc. 2004;79:541-5.

21. Bao C, Liu X, Zhang H, Li Y, Liu J. Coronavirus disease 2019 (Covid-19) CT findings: a systematic review and meta-analysis. J Am Coll Radiol. 2020;17:701-9.

22. Simpson S, Kay FU, Abbara S, Bhalla S, Chung JH, Chung M. et al. Radiological society of north america expert consensus document on reporting chest CT findings related to Covid-19: endorsed by the society of thoracic radiology, the American college of radiology, and Rsna. Radiol Cardiothorac Imaging. 2020;2:9. 